\title{
Traditional Process Foods of the Ethnic Tribes of Western Hills of Manipur, India
}

\author{
Thangjam Anand Singh", Prakash K. Sarangi and Ng. Joykumar Singh \\ AICRP on Post-Harvest Engineering Technology, Directorate of Research, Central \\ Agricultural University, Imphal, Manipur - 795004, India \\ *Corresponding author
}

\section{A B S T R A C T}

\begin{tabular}{|l|}
\hline Ke y w or d s \\
Zeliangrong, \\
Northeast India, \\
Process meat, Bamboo \\
shoot, Ethnic
\end{tabular}

The Western hills of Manipur, India are inhabited by tribal people mostly of Zeliangrong tribe and to some extent by Kuki tribe. They had been living in an isolated society with its own socio-cultural pattern and tradition. The seasonal food produce were processed to enhance nutritive value, flavour and above all shelf life to consume in the lean season. The most common method of processing is sun drying and natural fermentation and boiling in the plain water. Lack of or conscious efforts to limit salt uses were evident during the survey. The process food includes both plant based products, alcoholic beverage and animal based process food. The bamboo shoot in various process forms was most important plant based food items as it was available in plenty in the vast bamboo forest of the region. These traditional foods were considered rich in nutritional values and have healing properties. Hence, there should be purposeful efforts to revive and promote the traditional food habit systems among the villagers.

\section{Introduction}

The ethnic tribal people of North East India, particularly Manipur have been living in the forest ecosystem and follow their own sociocultural pattern, tradition and typical food habits. The traditional foods of tribal people are very simple and they used in festivals and rituals (Bareh, 2001). These traditional foods not only rich in nutrients but also used for curing of several diseases (Singh and Sureja, 2006). They depend mainly upon the natural resources of the habitat for their food. The ethnic and tribal people of North East Hill (NEH) of India are confined to their traditional food habits with traditional process food as an integral part. Diversity in tradition and culture among different communities in Manipur has resulted in a large variety of traditional food products. Varieties of products are being prepared from meat, fish and locally available vegetables, herbs, and spices. Among them, indigenously produced blood sausage, animal by-products with rice flour, maize, or fruits, dry meat powder with herbs, and special preparation from animal fats preserved in dry gourd or bamboo containers are important (Lalthanpuii et al., 2015). They utilised the rich traditional knowledge to prepare beverages, boiled foods, fermented foods and nutritionally rich traditional foods from various indigenous crop plants, forest 
products and meat of wild and domestic animals. These foods are an essential part of their social and cultural life.

Earlier studies reporting on the traditional food products of the region including Manipur, Mizoram, and Nagaland focus on the uniqueness and popularity of the products. Several anthropologists and ethno botanists have studied in alcoholic beverages of the different tribal peoples of North East (Singh and Singh, 2006). The dependence on livestock as an alternative source of income is significant in the agriculture sector in this region (Kumar et al., 2007). The traditional food products of Manipur were reported by several studies (Devi and Kumar, 2012; Jeyaram et al., 2009) include primarily fish and plant food items such as Iromba, Champhut, Kangshoi, Hawaijar, Soibum, Ngari, and Paknam. Medicinal properties obtained from spices that are added to the traditional products also enhance the functional property of the product in addition to the enhancement of flavor and nutritional value of the dishes. The synergistic effect of spices in fermentation is due to the presence of manganese in spices such as black pepper, mustard, garlic, nutmeg, cinnamon and mace (Bacus, 1984). Manganese in the fermented foods has been cited as a growth factor for cultures and has inhibitory factor for $S$. aureus and L. monocytogene, (Zaika et al., 1978; Kang and Gung, 2000). Taking into account the diversities of the traditional products, the popular ones can be identified to explore its prospective potential in context to commercialization (Singh et al., 2007).

The ethnic people of Tamenglong and Noney district in the western hills of Manipur have the knowledge of the cycle of various local wild plants and animals with their time tested indigenous knowledge. They have exploited the plant and animal resources of their habitat and lead a successful living harmoniously with the habitat. They collect the seasonal vegetables and food items and processed and stored for yearlong consumption during lean season. Fermentation and sun drying are the basic method for processing for this people. Their important diet consists of rice, meat, fish and vegetables. Fruits of different kinds are also taken by them. Preparation of food is simple, in most cases, meat, fish or vegetables are cooked only with salt, chilly and indigenous species or meat cooked with some vegetables. Historically, the use of oil to fry food items was totally unknown to tribal people of the region living in these remote areas. They still rarely use oil in the preparation of food. In short, food is cooked simply by boiling, adding salt and chilli and spices are rarely used. Vegetable or meat cooked with grain rice is the common delicious food item of the people living in the region. The limited produces from the natural forest were generally collected in season and stored after processing like cooking, drying and fermenting. Processing of these seasonal foods not only enhanced its shelf life but also enriched nutrient and flavour. They are very fond of fermented foods. They often flavour their simple curries with different kind of fermented food items and herbs. The women folks process traditional fermented foods, such as vegetables and beverages. The popular raw materials for fermented food items are: bamboo shoots, soybean, seed of Indian rosselle etc. With gradual introduction of readymade foods, western and oriental foods are easily available; lead to change in dietary habit thereby decrease the consumption of traditional ethnic foods. The study aims at documentation and preserving of traditional process foods and its indigenous traditional knowledge of the region.

\section{Materials and Methods}

The present study is conducted in the seven villages in the two districts, Tamenglong and 
Noney, of Manipur. The majority of tribal of this region belong to Zaliangrong tribe and to lesser extent Kuki tribe. About 20 persons each with traditional knowledge and currently practicing in production of the ethnic foods were selected from the study sites of seven villages namely Noney, Nungba, Awangkhul, Keithelmanbi, Khonsang, Duithangjam and Khoupum.

The selected key informants were interviewed through structured and unstructured enquiries at the study sites to get supportive information. The response of the informants was recorded and analysed. The secondary sources were also collected from available books, journals, electronic and non-electronic sources.

\section{Results and Discussion}

Preparation of traditional process foods and their uses along with their implication are described in this study (Fig. 1-4).

\section{Plant based traditional process food}

\section{Tunateinzi}

Tunateinzi is prepared in festivals and other social functions. Rice is soaked in clean water for 2-3 hours and then dried on bamboo basket and powder by grinding in a mortar. The rice flour is now mixed with sugar for taste and Tunateinzi is prepared. There are two methods of preparing Tunateinzi. In boiled method, the mixture is made into dough, which is then wrapped with banana leaves and tied properly. It is then cooked in boiling water for about one hour. Such bread is called Koutianji and it can be kept for about a week. In second method, the mixture is made softer by adding some water and made to round form. Thus prepared dough is grilled over charcoal hearth until it becomes blacken. The black or burn portion is removed while eating.

\section{Lengchiphon}

The rice powder was prepared like mentioned elsewhere and mixed with a small amount of sugar liquid for flavour and the mixture is poured in a specially designed earthen that has a hole at the bottom pot. The hole is closed by banana leaves before putting the mixture. It is then covered with a tight lid and placed on a boiling water pot to cook by the steam of water for about one hour. After one hour Lengchiphon is ready to use.

\section{Ganang Tamdui}

Mustard leaves are collected from jhum field during winter and put on a platform for some days until the colour of leaves turn into yellow. The leaves are put in the sun again and the weathered leaves are pressed in a bamboo culm cover lightly with banana leaves and mud. After some days, when a pungent smell is released the leaves are removed and pressed with both hands in order to extract the liquid from the leaves. Next, the liquid is boiled in a pot to condensed liquid. This liquid is called Ganang Tamdui. It can be preserved for about one year by keeping in a tightly closed container. Ganang Tamdui, the liquid of fermented mustard leaves is mainly used in preparation of Tam, an ethnic soup. In second method, the mustard leaves are boiled and spread in the sun. After that the leaves are placed in a pot covered with plantain leaves for fermentation. Similar product, known as Inziang sang is prepared and consumed by the ethnic people of Nagaland (Mao and Odyuo, 2007). Ganang tamdui is used as taste enhancer in various preparations.

\section{Ganang Kang}

The mustard leaves which are collected from jhum field in winter season are boiled in a pot with small amount of water and spread in the sun until the leaves become completely dry. 
The leaves are made into pieces for quick dry. They are usually preserved placing above the fire place for use in rainy season/off season. This product is largely different from the Gundruk, a lactic acid fermented mustard leaves (Tamang, 2009) of Sikkim and Darjeeling of India.

\section{Bi-kang}

Seasonal Colocasia arum were collected and boiled for about 2 hours and the water was drained off. Then it is placed on the bamboo tray and kept on the rooftop for drying. $B i$ kang is dried in 3 - 5 days depending on the intensity of the sunlight. The dried colocasia can be stored as long as a year. It is used in cooking with meat during rainy season when there is lean period of food collection.

\section{Bi kuang kang}

The petiole of the Colocasia plant is also very important food item and is considered not less than the rhizome of the plant. The petioles collected from field were bound together and hang near the fireplace as whole except rhizomes. This is kept for at least 3 months and can be kept as long as two years. The slow drying and possibly Lactic acid fermentation would have reduced/remove the oxalate content. This product can be cooked with meat and other vegetables or can be consumed as such in Tam preparation.

\section{Khui}

Khui is a traditional fermented soybean with characteristic flavor and stickiness. It is commonly consumed in local diet as a source of protein. In the traditional method of Khui preparation, soybean seeds which are cleaned and sorted are dipped in water for about 10 hours. Then, the seeds are washed in plain water two or three times and cooked by boiling. The boiled soybeans are drained off; then wrapped in banana leaves and put above the fire place for about three days in summer/ five days in winter so as to let the process of fermentation complete properly and also to keep away from insects' damage. Khui thus prepared is used in curry and chutney preparation along with chilly and salt. However, for long-term storage and depending on choice of taste, the fermented Khui are dried in cake form above the fireplace or dried in the sun and stored in containers. The dried beans or cakes are cooked with meat or are used for the preparation of Tam, o local delicacy. The traditional Khui is characterized by its stickiness, alkalinity, and pungent odour. This fermented soybean product is similar to hawaijar of valley people of Manipur (Jeyaram et al., 2008), kinema of Sikkim (Tamang et al., 2009) and Darjeling, Bekang of Mizoram and Tungrymbai of Meghalaya (Chettri and Tamang, 2014). It serves as a cheap source of high quality protein food to the ethnic people from the ancient times.

\section{Gankhiang-khui}

It is an alkaline fermented food product from seeds of Hibiscus canabinus which is similar to Bikalga, Furundu (Parkouda et al., 2008; Al Bahi and Abdelgadir, 2012) in Africa where the seed used were of $H$. sadarifa. The leaves of the plant are consumed as a popular vegetable during summer and the bast fibre is used for making crude fibre for making rope. The seeds are used for preparing Gankhiangkhui by natural fermentation.

The process of preparation of Gankhiagkhui is similar to that of Khui and it is used in making Tam along with chilli and salt. For longer storage the gankhiang khui is mixed with common salt at about $1.5 \%$ and packed tightly in bamboo culms which not only enhances the shelf life of the product but also have unique flavour. 


\section{Bamboo shoot (Thun) items}

There is vast natural bamboo forest which provide almost unimaginable amount of bamboo shoots during the rainy season. Preparation of various process bamboo items from abundantly available resources is inevitable. Bamboo shoot is also a popular item of food. It is taken fresh by boiling or roasting in the hot ashes of the fire or preserved dried or fermented to get sour bamboo shoot preservation.

Thunkheng (whole succulent shoot) and Thunbin (slice bamboo shoot) are fermented bamboo shoot produced exclusively from succulent bamboo shoots of the species Dendrocalamus hamiltonii, D. sikkimensis, D. giganteus, Melocana bambusoide, Bambusa tulda and B. balcona. Fermentation process of Thun, bamboo shoot is carried out during May to June when new shoots sprout. Tender bamboo shoots after removing the scales are sliced into thin small pieces and put in an earthen pot or a Khoupak, bamboo basket with the inner wall lined with banana leaves to keep in air tight condition. A hole is made at the bottom of the basket/pot for draining the liquid.

The upper portion of the basket or pot is covered with banana leaves and stones are put on it as weight. Large scale fermentation is done in a pit. These products are similar to Soibum, Eup, Mesu, Khorisa, Hirring of other region of NEH India (Tamang and Tamang, 2009). Some of the bamboo shoots get fermented within five days. The fermented bamboo shoot is also known as Thunkheng. Such short duration fermentation occurred through three phase succession of autochthonous lactic acid bacteria (Romi et al., 2015). Bacillus spps and Lactic acid bacteria are the major fermenting microbes in Soidon, another similar product which is produced solely using a particular bamboo locally known as naat (Jeyaram et al., 2010). For longer storage, the fermented bamboo shoots are also dried in the sun. Thunkhengkang, the dried bamboo shoots are graded according to size for preparing different dishes. Thus, two products of fermented bamboo shoots, wet and dry are obtained. The products are used in cooking meat or vegetable dishes. There is another method in preparation of dry bamboo shoots. For this purpose, any edible bamboo shoot variety is used. All the bamboo shoots are cut into pieces and boiled with water and then the shoots are exposed to the sun for drying. Both the process of fermentation and boiling prior to drying removes the glycocyanides usually present in bamboo shoot. These dried bamboo shoots are kept in a basket to use in off season. The bamboo shoots are rich in potassium, carbohydrates, dietary fibres, vitamins, antioxidants and various medicinal properties (Satya et al., 2010).

\section{Edible wild mushrooms}

Wild edible mushroom from the forest is collected and cleaned and sundried. The duration of drying is usually 3-5 days although it is largely depend on the weather. The Sinukon (Auricularia auriculari), Pantum (Schizophyllum commune) and Panei (Lentinula edodes) were among the major wild mushroom collected during season. The dried products were stored for yearlong uses or sold in the local market.

The exotic taste, high nutritive value and possess medicinal properties of these mushroom (Choudhary et al., 2015) commands very high price in local market. The local people have the indigenous knowledge of identifying edible wild mushrooms from the poisonous ones. Many other unidentified minor species were also collected and consumed by the ethnic people of the region. 
Fig.1 Alcoholic beverages production $a$. Zouju preparation in household level, b. Khai, c. Zouju stored in earthen pot

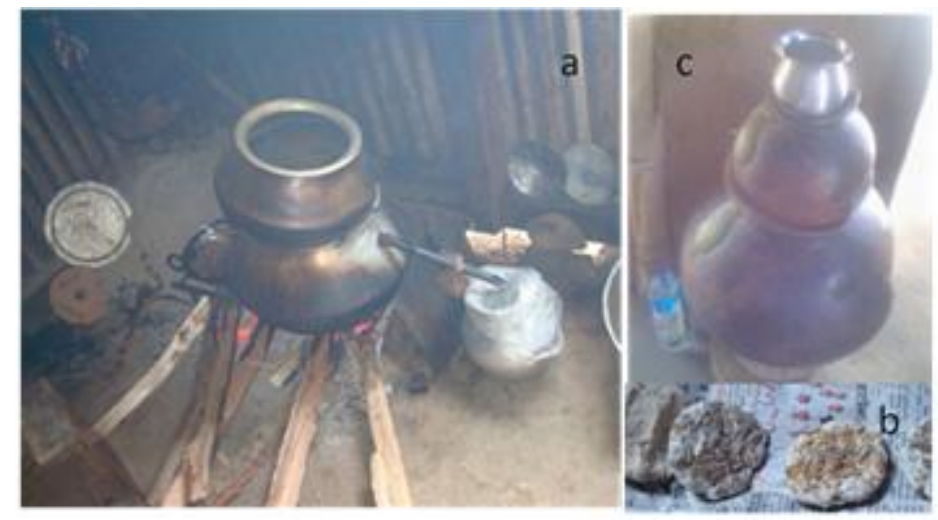

Fig.2 Plant based traditional process food

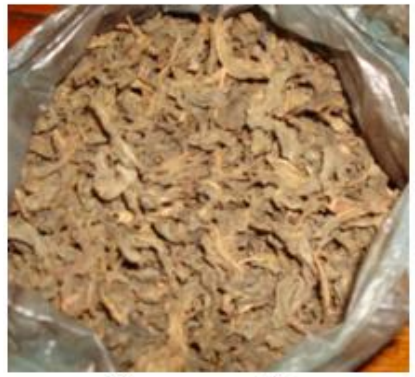

a. Ganang Kang

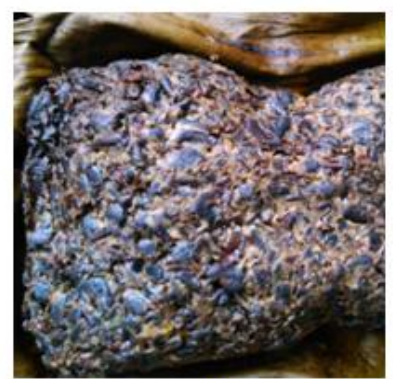

d. Gankhiang-khui

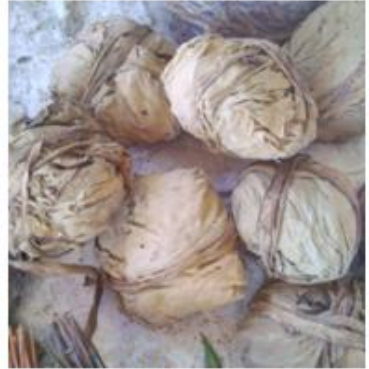

b. Bikuang Kang

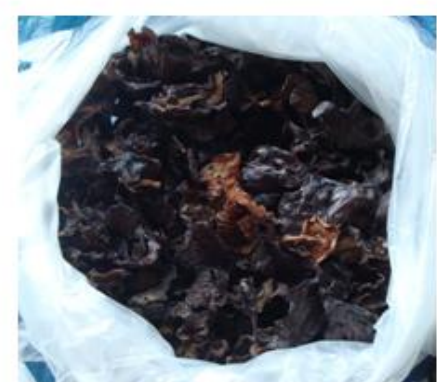

e. Sinukon

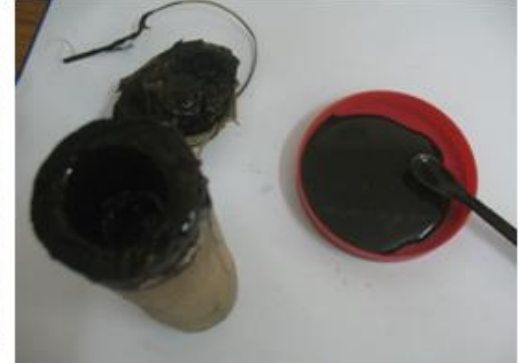

c. Ganang Tamdui

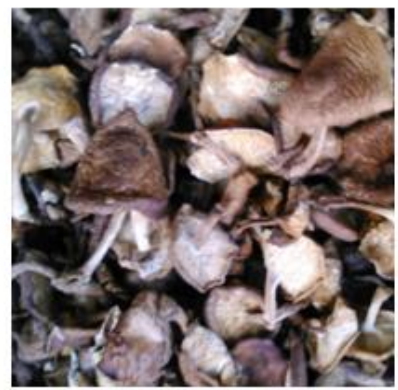

f. Panei

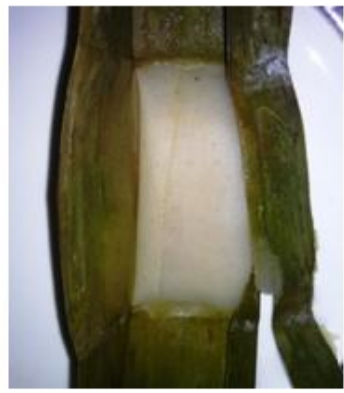

g. Lengchiphon 
Fig.3 Traditional process Bamboo shoot products

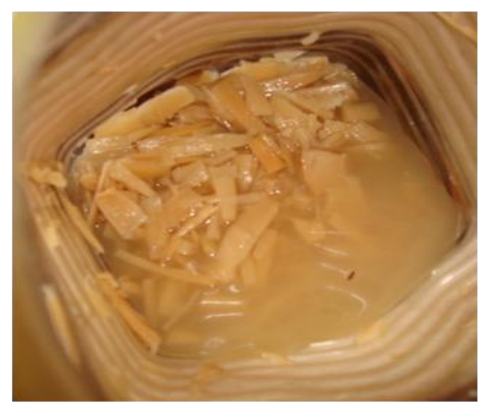

a. Thunbin

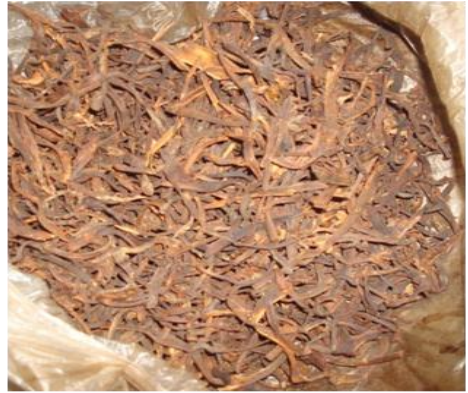

b. Thunkang

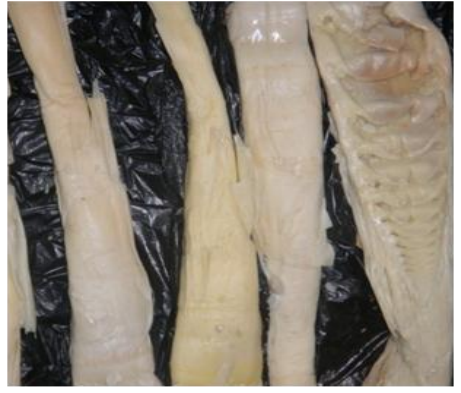

c. Thunkheng

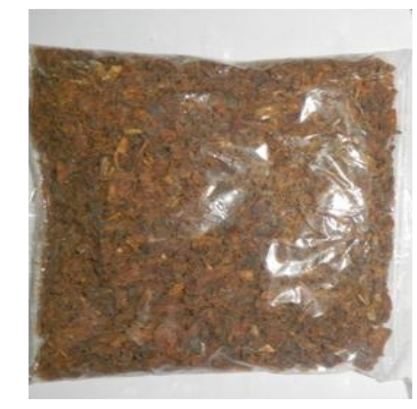

d. Thunbinkang

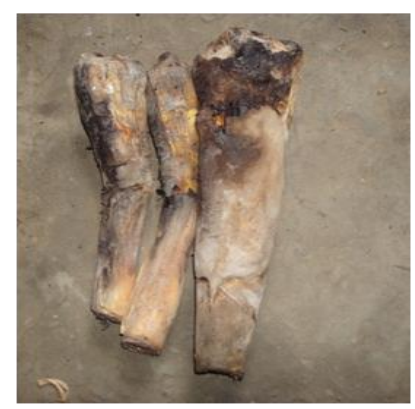

e. Thunrou

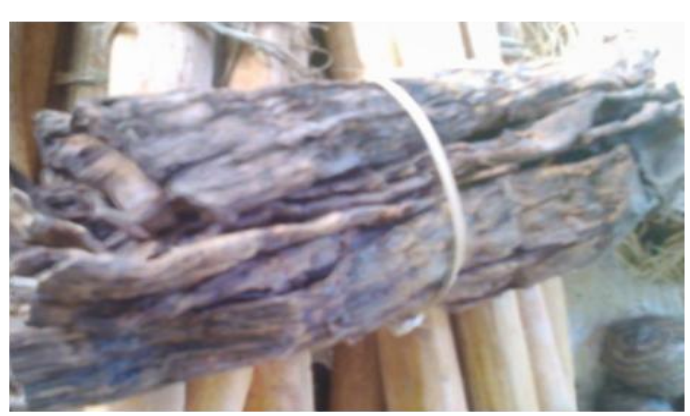

f. Thunkhengkang

Fig.4 Animal based traditional process food
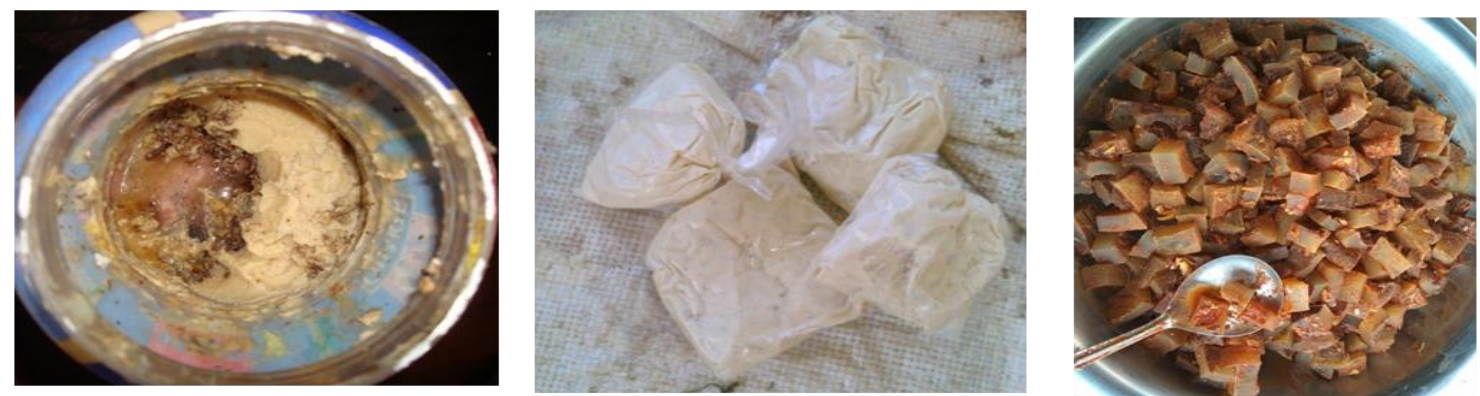

a. Zanhtha lummei

b. Zanhtha lummei (Beef)

c. Guaihgi kang Tam

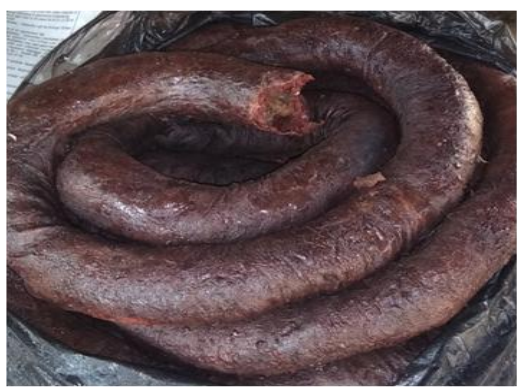

d. Jeytein

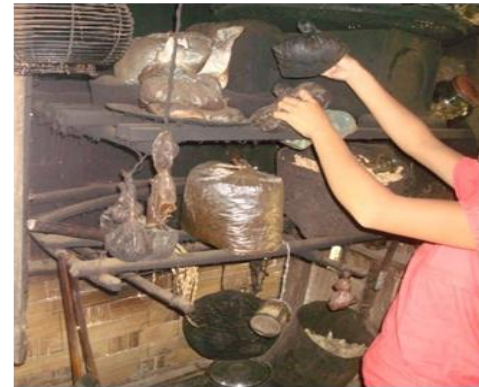

e. Drying and storing food items near the fireplace of traditional kitchen 


\section{Traditional alcoholic beverages}

\section{Khai}

For preparation of Khai, rice is soaked in water for about 1-2 hrs and collected in a bamboo mat. Thereafter, it is made into powder by grinding in a mortar. The rice powder is properly mixed with the bark powders of Khaipuroi. The mixture is added water slowly till the mixture made into paste with the requisite consistency. The paste is then made into small rounded cakes and the same cakes are placed on the paddy husk. It is required to cover by a cloth to accelerate the fermentation process. Khai is similar to Hamei of the Meitei people of Manipur (Jeyaram et al., 2009). After 6-7 days, the cake is ready to use and for preservation.

\section{Zoungao}

The local people use different types of alcoholic beverages prepared from rice. It is commonly known as Zou. In the alcoholic beverages yeast, Khai is needed for fermentation. For preparation of Zoungao, rice beer, rice is soaked for about 1-2 hrs in water along with some germinated paddy. Then, the mixture is made into powder with the help of mortar and pestle. The crushed rice is poured cautiously in a wooden barrel called $\mathrm{Bu}$ or earthen pot and then hot water is added in it.

The mixture was well churned with a wooden stirrer until it becomes completely cool down. More water was added again to the desired level and the $\mathrm{Bu}$ or pot is covered with banana leaves and kept 3-4 days in a place without any disturbance. Within these days, form started coming out and a typical flavor is released. This is an indication that the Zoungao is now ready to use. Consumption of rice beer is considered not only good for health, but also good for fair complexion, when used within 3-4 days. These people drink it instead of tea. It is also used in ritual ceremony.

\section{Timpui}

Timpui, a kind of alcoholic beverage is prepared from fermented cooked rice. Rice was cooked and spread in a round basket made of bamboo. Khai is mixed thoroughly with the cooked rice and then the mixture is put in an earthen pot already cleaned and dried in the sun. A little amount of water is poured just to dip it and then the pot is placed in a proper place for fermentation. In winter, the pot is covered with a Colocasia leaf for fermentation. Heat along with a pungent smell is released after 3 or 4 days, after which, water is poured an approximate ratio of 4:3. After $8-10 \mathrm{hrs}$, the liquid called Timpui is ready to use. In summer, it takes 3-4 days and in winter 6-7 days of fermentation.

\section{Zouju}

Zouju, a strong alcoholic beverage is prepared from Timpui. Preparation of Zouju is same with that of Timpui up to the stage of the fermentation of cooked rice. This Timpui is poured in a suitable pot called Zoulai and boiled in low flame. The pot is covered with an aluminum funnel and from this a pipe is connected to the outer part of the pot, this pipe is for collection of distilled liquid, Zouju.

On the funnel, a pot containing cold water is placed just to restrict the evaporation outside and to condense the vapour into liquid. Between the pot and funnel, a plate having holes is placed. All the connecting points are sealed with mud. Distillation will continue until the alcohol present in the Timpui is completely out. The residual content is used as pig feed. Zouju is stronger than Zoungao. These alcohols are also use as medicine in many folk medicine (Singh and Singh, 2006). 


\section{Animal based traditional process food}

\section{Zanhtha lummei/Sathu}

Usually, fat of internal portion of the pig or cow is preserved in a bamboo tube covered tightly with a lid. The tube is placed above the fire place for 20 days to allow natural fermentation. It is used in preparation of curry to soften the vegetables and it also imparts nice taste to the curry. The product is very similar to Sa'um of Mizoram though they exclusively use pig only. High population of Proteus mirabilis, a potential pathogen that causes urinary tract infection was reported in marketed sa'um (Singh et al., 2014), similarly, it could also harbour the same microorganism though no case of food poisoning was reported till that while consuming the product.

\section{Jeytein}

It is perhaps the most popular process meat product of this region. It is a type of traditional sausage. Jeytein is prepared from the Intestine of animal, preferably that of pig. The intestine was washed meticulously and loaded with blood, liver and other internal organ of the animal mixed with spices particularly ginger and turmeric, chilli, salt and local herbs. It is cooked for about 2 hours in boiling water or until it is cooked nicely. The intestine is then prick with small bamboo needle to removed water. The drain product can be stored in container for weeks. Prior to eating this item, it is usually fried or roasted. Thus the non-meat part of animal is converted to a delicious food item.

\section{Guaihghi kang}

It is the roasted skin of cow that was slaughter for meat. It is kept for drying in the traditional kitchen, above the traditional hearth. This product is used in preparation of a local delicacy known as Guaihghikang tam. Therefore, there is hardly any part of animal that is not used as food item. Similar product known as Guakmai tam is prepared from roasted pig tail.

Like many other tribal communities of the world, they also have their system of preparation of food and preservation. They practice different systems of preservation of food to avoid from the apprehension of scarcity of food in rainy season.

This clearly indicates that the hill people bear hard life in the struggle of survival. The changes in food habit might have resulted in many diseases notably heart disease, diabetes and anaemia particularly to pregnant and lactating women. Although they have adopted to new food habits in modern times, the ethnic foods are important and have cultural values. It is therefore imperative to document the traditional foods and their importance among the people.

In tribal society, culture, traditions, ethics and food habit can't be separated or looked separately as they are all interrelated. Nowadays, their approaches to life have changed totally and it is not easy to find the age-old simple life style even in the villages. Traditional foods are still a favourite item in the food preparation.

The advent of modern civilization has adversely affected the age-old tradition and thus the younger generations of tribal people of the region are not exposed to traditional practices. As the rich nutritional values of traditional foods and its healing properties are well known, there should be purposeful efforts to revive and promote the traditional food habit systems within villagers. The nutritional and microbiological aspects of traditional foods are required to be investigated in future. 


\section{Acknowledgement}

Indian Council Agricultural Research (ICAR), Government of India is duly acknowledged for providing financial support to AICRP on Post-Harvest Engineering and Technology, Imphal Centre. We are grateful to people of Tamenglong and Noney Districts for providing valuable information for this article.

\section{References}

Al Bahi, A. A. and Abdelgadir, W. S. (2012) Effects of Dietary Furundu (Fermented Hibiscus sabdariffa Seed) Supplementation on the Performance, Some Blood and Serum Parameters and Histopathology of Wistar Rats. Advance Journal of Food Science and Technology 4(2): 64-69.

Bacus, J. (1984) Utilization of microorganisms in meat processing. Research Studies Press LTD, Wiley, Letchworth, Hertfordshire, England, New York. p1-170.

Bareh HM, Encyclopaedia of NEG region. I. Arunachal Pradesh. Mittal Publication, New Delhi. 2001. 2-233.

Chettri, R and Tamang, J. P. (2014) Bacillus species isolated from tungrymbai and bekang, naturally fermented soybean foods of India. International $\mathrm{J}$ food microbiology

DOI: 10.1016/j.ijfoodmicro.2014.12.02 1

Choudhary, M., Devi R., Datta A., Kumar, A., Jat H. S. (2015) Diversity of Wild Edible Mushrooms in Indian Subcontinent and Its Neighbouring Countries. Recent Advances in Biology and Medicine, 1:69-76.

Devi, P. and Kumar, P. (2012) Traditional, ethnic and fermented foods of different tribes of Manipur. Indian J. Tradit. Knowledge, 11(1): 70-77.
Jeyaram K, Mohendro Singh W, Premarani T, Devi AR, Chanu KS, Talukdar NC, Singh MR (2008) Molecular identification of dominant microflora associated with 'Hawaijar' - a traditional fermented soybean (Glycine max (L.)) food of Manipur, India. Int $\mathrm{J}$ Food Microbiol 122(3):259-68.

Jeyaram K, Romi W, Singh TA, Devi AR, Devi SS (2010) Bacterial species associated with traditional starter cultures used for fermented bamboo shoot production in Manipur state of India. International Journal of Food Microbiology, 143: 1-8.

Jeyaram K, Singh TA, Romi W, Devi AR, Singh WM, Dayanidhi, M Singh, Tamang JP (2009) Traditional fermented foods of Manipur. Indian Journal of Traditional Knowledge, 8: 115-121.

Kang, D.H. and Gung, D.Y.C. (2000) Stimulation of starter culture for further reduction of foodborne pathogens during salami fermentation. J. Food Prot., 63: 1492-1495.

Kumar, A., Staal, S., Elumalai, K. and Singh, D.K. (2007) Livestock sector in NorthEastern region of India: An appraisal of performance. Agric. Econ. Res. Rev., 20: $255-272$.

Lalthanpuii, P.B., Lalruatfela, B., Zoramdinthara and Lalthanzara, $\mathrm{H}$. (2015) Traditional food processing techniques of the Mizo people of Northeast India. Sci. Vision, 15(1): 3945.

Mao, A. A. and Odyuo, N. (2007) Traditional fermented foods of Naga tribes of Northeastern India, Indian J. Tradit. Knowledge, 6(1): 37-41.

Parkouda, C., Diawara, B., and Ouoba, L. (2008) Technology and physicochemical characteristics of Bikalga, alkaline fermented seeds of Hibiscus 
sabdariffa. African Journal of Biotechnology 7(7):916-922.

Romi, W., Ahmed, G., and Jeyaram, K., (2015) Three-phase succession of autochthonous lactic acid bacteria to reach a stable ecosystem within 7 days of natural bamboo shoot fermentation as revealed by different molecular approaches. Molecular ecology 24(13): 3372-3389

Satya, S., Bal, L. M., Singhal, P. and Naik S.N. (2010) Bamboo shoot processing: food quality and safety aspect (a review) Trends in Food science and technology, 21:181-189

Singh RK and Sureja AK (2006). Centuriaon Women and diverse Knowledge systems. Indian Journal of traditional knowledge. 5(3): 413-419.

Singh T.A., Devi, K.R., Ahmed, G., and Jeyaram, K (2014) Microbial and endogenous origin of fibrinolytic activity in traditional fermented foods of Northeast India. Food Research International. Food Research International 55:356-362.

Singh, A., Singh, R.K. and Sureja, A.K. (2007) Cultural significance and diversities of ethnic foods of Northeast India. Indian J. Tradit. Knowledge, 6(1): 79-94

Singh, P. K. and Singh, K. I. (2006) Traditional alcoholic beverage, $Y u$ of Meitei community of Manipur. Indian J. Tradit. Knowledge, 5(3): 184-190.

Tamang JP (2009) Himalyan fermented foods: Microbiology, nutrition and ethnic values. Talylor \& Francis group, CRC press, Boca Raton.

Tamang JP, Chettri R, Sharma RM (2009) Indigenous knowledge of Northeast women on production of ethnic fermented soybean foods. Indian Journal of Traditional Knowledge, 8: 122-126.

Tamang, B. and Tamang, J. P. (2009) Traditional knowledge of biopreservation of perishable vegetable and bamboo shoots in northeast India as food resources. Indian J. Tradit. Knowledge, 8(1): 89-95.

Zaika, L.L., Zell, T.E., Palumbo, S.A. and Smith, L.J. (1978) Effect of spices and salt on fermentation of Lebanon bologna-style sausages. J. Food Sci., 43: 186-189.

\section{How to cite this article:}

Thangjam Anand Singh, Prakash K. Sarangi and Joykumar Singh, Ng. 2018. Traditional Process Foods of the Ethnic Tribes of Western Hills of Manipur, India. Int.J.Curr.Microbiol.App.Sci. 7(10): 1100-1110. doi: https://doi.org/10.20546/ijcmas.2018.710.121 